Section Editors

David C. Spencer, MD

Steven Karceski, MD

Steven Karceski, MD

\title{
Seizures after bleeding into the brain
}

WHAT DID THE AUTHORS DO? In their article, "Electrographic seizures and periodic discharges after intracerebral hemorrhage," Dr. Claassen and colleagues discuss several important issues that affect people who have bleeding into the brain (Neurology 2007; 69:1356-1365). They used a retrospective review to study problems associated with bleeding within the brain. There are problems with this type of study. However, it is this kind of study that often leads to further research.

In a retrospective study, the authors select a group of people with a particular problem or illness. For instance, the authors might look for a group of people who have migraines. They start carefully looking for problems that the group share. For instance, many people with migraine take pain medications. In a retrospective study, the use of pain medications would be something shared by a large number of these people. Two statements are possible. The first is that people who are in pain are more likely to take a pain medication. A second possibility is that the medication caused the headaches. Remember that the retrospective study only shows those things that a group of people have in common. It does not necessarily tell us whether the illness caused a problem or vice versa.

WHAT DID THE AUTHORS FIND? Dr. Claassen et al. studied a group of people who had intracerebral hemorrhage. There were 615 people admitted to Columbia-Presbyterian Hospital with this diagnosis between January 1, 1998, and September 9, 2006. Of this group, 102 had testing called continuous electroencephalography (cEEG). In other words, 102 people had an EEG that ran for an average of 3 days. Many of these people were in the intensive care unit (ICU). Many were very sick, and were not responding well to treatment. In most cases, their doctors ordered the EEG because the person was not getting better.

The people with intracranial hemorrhage received many treatments. Medicines were used to treat high blood pressure. Other medicines were administered to treat the swelling that occurs when a person has a bleed in the brain. Some people needed surgery to keep the brain from swelling so much that they would die. Others had high fevers, and were treated with a special blanket that helped to bring down their temperature.

All of the people had a computed tomogram (CT) of the head. Most had several CT scans, designed to see if the bleeding had stopped, or was still happening. Using measuring techniques, the doctor determined the volume of intracerebral blood. By comparing sequen- tial CT scans, the doctor could determine if the bleeding was getting worse. Dr. Claassen et al. found that if a person's bleed got worse in the first 24 hours, he or she was more likely to have seizures.

The EEG used standard techniques to record brain waves. The EEG showed seizures in 1 out of 5 people $(18 \%)$. More than half $(56 \%)$ had a seizure within 1 hour of starting the EEG. Three-fourths $(72 \%)$ of people who had seizures experienced one in the first 24 hours of the recording. Almost all (94\%) had a seizure in the first 2 days of the recording. What is interesting about this that there was only one person in whom the seizure was obvious to the medical staff. In other words, without the EEG recording, the seizures would have not been recognized in 17 of the 18 people who were having them.

These findings are important for several reasons. First, seizures are common. They occurred in onethird of people who had bleeding within the brain. However, more than one-half $(17 \%)$ of this group had seizures that could not be recognized simply by watching the patient. Instead, cEEG was needed to detect the seizures. In 9 out of 10 people (94\%) who had seizures and an EEG, the EEG captured the seizure in less than 2 days.

In addition to seizures, the cEEG also showed markers of seizures called periodic discharges. These markers are not seizures. Instead, they are brain wave patterns that tell doctors that seizures are more likely to happen. One-fifth $(17 \%)$ of people had these markers. Often they also had seizures. Dr. Claassen et al. did not find an association between seizures and a poor outcome. Instead, they found that the presence of periodic discharges occurred more often when a person was doing badly.

WHAT DOES THIS MEAN? Retrospective studies are sometimes difficult to interpret. People who have intracerebral hemorrhage are likely to have seizures. Sometimes, the seizures are so subtle that they can only be "seen" with medical testing such as cEEG. This study showed that one-half of people who had seizures needed EEG to discover the fact. This suggests that when a person is admitted to the hospital because of bleeding within the brain, cEEG should be considered. At present, this is not a technology that is available everywhere. This study shows the importance of this kind of testing in this specific situation.

In addition, the study showed that the presence of periodic discharges on EEG was associated with a poor outcome. This is an EEG finding only. In other words, the study highlights a second reason for doctors to consider cEEG in people with intracerebral hemorrhage. 
WHAT IS AN INTRACRANIAL HEMORRHAGE? Intracranial hemorrhage means bleeding somewhere inside the skull. It is often referred to as a hemorrhagic stroke. There are two kinds of bleeding in the skull. The first occurs in the brain substance itself. This is called intracerebral hemorrhage. The subarachnoid space surrounds the brain, and is filled with a clear fluid called CSF. The brain floats in this watery layer. The water protects the brain, and cushions it from sudden trauma. If bleeding occurs into this watery layer, and not into the brain itself, it is called a subarachnoid hemorrhage. In some people, both will occur at the same time.

WHAT IS AN ANEURYSM? The blood vessels that go to the brain run through the subarachnoid space. Sometimes, a person develops an aneurysm. Aneurysms are like balloons that form on the blood vessels themselves. As the "balloons" grow in size, the walls become thinner. At some point, the "balloon" may break, releasing the blood. When this occurs, it is called a subarachnoid hemorrhage. Subarachnoid hemorrhages are very serious. If not treated immediately, they can cause death.

BLEEDING WITHIN THE BRAIN The second kind of bleeding occurs in the brain substance itself, called intracranial bleeding. There are many causes of bleeding within the brain. One of the most common is head trauma. Head trauma can be caused by traffic accidents, falls, sports injuries, or acts of violence.

Second to this is high blood pressure. As the heart beats it pumps blood to the arteries and creates a pressure from the blood pumping into the arteries and the pressure that occurs when the arteries resist the blood's flow. Blood pressure changes with the strength of the heartbeat and depends on the flexibility of the artery walls. Blood pressure is constantly changing depending on physical activity, medications taken, emotional state, and temperature. If blood pressure goes high enough, it can cause blood vessels to burst, resulting in bleeding into the brain.

Some people are born with an abnormal tangle of blood vessels (called a vascular malformation) in their brain. Usually, this type of malformation is present at birth. Because the blood vessels are abnormal, they may have very thin walls. Like aneurysms, if they are thin enough, they may break and cause bleeding.

Bleeding within the brain is serious and requires urgent treatment. Often a person with intracranial bleeding will stay in the intensive care unit until they are stable. 


\title{
Neurology
}

\author{
Seizures after bleeding into the brain \\ Steven Karceski \\ Neurology 2007;69;E13-E14 \\ DOI 10.1212/01.wnl.0000285507.50682.58
}

This information is current as of September 24, 2007

\section{Updated Information \&}

Services

Permissions \& Licensing

Reprints including high resolution figures, can be found at: http://n.neurology.org/content/69/13/E13.full

Information about reproducing this article in parts (figures,tables) or in its entirety can be found online at:

http://www.neurology.org/about/about_the_journal\#permissions

Information about ordering reprints can be found online:

http://n.neurology.org/subscribers/advertise

Neurology ${ }^{\circledR}$ is the official journal of the American Academy of Neurology. Published continuously since 1951, it is now a weekly with 48 issues per year. Copyright. All rights reserved. Print ISSN: 0028-3878. Online ISSN: 1526-632X.

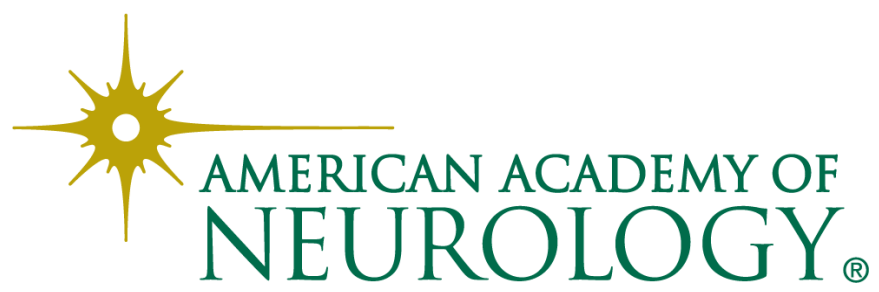

